\title{
Comparison of Two Quantitative Evaluation Methods for Assurance Cases
}

\author{
Nobuyuki KOBAYASHI $^{\text {* }}$, Aki NAKAMOTO ${ }^{\text {, }}$, Maki KAWASE ${ }^{c}$, Seiko SHIRASAKA $^{\mathrm{d}}$
}

\author{
a Development Administration Department, KATO WORKS CO., LTD.,, \\ 1-9-37 Higashioi, Shinagawa-ku, Tokyo 140-0011 Japan \\ ${ }^{b}$ The System Design and Management Research Institute of Graduate School of System Design and Management, \\ Keio University, 4-1-1 Hiyoshi, Kohoku-ku, Yokohama-shi, Kanagawa 223-8526 Japan \\ ${ }^{c}$ Education and Venture Creation Division, Center for Collaborative Research and Community Cooperation, \\ Hiroshima University, 2-313 Kagamiyama, Higashi-Hiroshima, Hiroshima 739-8527 Japan \\ ${ }^{d}$ Graduate School of System Design and Management, \\ Keio University, 4-1-1 Hiyoshi, Kohoku-ku, Yokohama-shi 223-8526, Japan
}

\begin{abstract}
This study shows a process of designing and comparing two quantitative evaluation methods for the structure of assurance cases (AC), which use two description methods: Goal Structuring Notation, and Dependability Cases. The International Organization for Standardization has mandated organizations to include AC in ISO 26262 and recommended to include AC in other standards. This study proposes two quantitative evaluation methods designed by authors, and assesses the necessity and effectiveness of the methods based on the results of quantitative evaluation of AC to confirm if the methods are useful for work improvement. We used a questionnaire completed by third party employees who are 1) working in an organization with written work procedures developed in Japanese organizational culture, 2) working in the manufacturing industry, and 3) engaged in daily routine work. These conditions define how written work procedures and documents have been created at each participant's workplace. Since we use these written materials as evidence to evaluate ACs, they satisfy certain conditions for preparation of the written information.

After showing previous research on assurance cases and presenting a procedure of quantitative evaluation, we propose two equations for quantitatively evaluating a sub-goal. One equation simply integrates the numbers of Evidence and Monitoring. The second equation takes into account users' opinion on Evidence and Monitoring to quantitatively evaluate an optional sub-goal. We then describe and discuss the results of a questionnaire on the two quantitative evaluation methods for assurance cases, one using Eq. 1 and the other using Eq. 2. Responses were given quantitatively on a seven-point ordinal scale and qualitatively in a free descriptive space. We then assessed effectiveness and necessity of the two methods. The results were statistically significant for both "effectiveness" and "necessity," And we found that Eq.1 suggested more efficacy than Eq.2. This paper concludes with future research topics.
\end{abstract}

Key words: Assurance Case, Goal Structuring Notation, Dependability Case, Evaluation Method

\section{Introduction}

Assurance cases have recently attracted attention as an international standard mandated by ISO 26262 [1] and other standards [2]. Making assurance cases more effective is important to ensure that they can be used efficiently to manage documents and processes in systems engineering. No methods, however, have been proposed and assessed to evaluate assurance case quantitatively. Kobayashi et al. [3] argued that it is difficult to carry out all work improvements simultaneously in case someone tries to achieve work improvement with the assurance case. First we quantitatively evaluate assurance cases to grasp the status and progress of daily work. The results from the evaluation can be used to manage documents and processes effectively.

This study aims at confirming the effectiveness if using the results from the quantitative evaluation about two assurance cases is beneficial for work improvement under constrain conditions described below. The study also proposes two quantitative evaluation methods for assurance cases.

Assurance cases essentially state the evidence supporting the goal, which depends on the evaluation of

*Corresponding author: n-kobayashi@kato-works.co.jp

Received: February 27, 2016

Accepted: October 24, 2016 
manuals and documents, and thus the evaluation of the methods proposed in this study significantly varies depending on organization formats. This study therefore assesses the necessity and the effectiveness of the two quantitative evaluation methods with the assessment limited as follows (see Table 1).

Table 1: Table captions should be placed above table

\begin{tabular}{|l|l|}
\hline \multicolumn{1}{|c|}{$\begin{array}{c}\text { Limitation for } \\
\text { Assessment }\end{array}$} & \multicolumn{1}{c|}{ Setting } \\
\hline Manual characteristics & $\begin{array}{l}\text { Made in Japanese } \\
\text { organizational } \\
\text { culture }\end{array}$ \\
\hline Type of industry & Manufacturing \\
\hline Type of work & Routine work \\
\hline
\end{tabular}

Firstly, the assessment is made in context of Japanese manuals and the organizational culture they were created in. Masuzawa pointed out the differences between Japanese and American manuals, stating that for example, Japanese manuals are not detailed in their step-by-step procedural descriptions [4]. Secondly, the assessment is made in relation to particular types of manufacturing industries taking into account the differences in evaluators' perspectives relative to the industry. Thirdly, employees are assessed with routines assuming a difference in routine work and non-routine work, which would affect the evaluation.

This study assesses the necessity and the effectiveness of the two quantitative evaluation methods based on a questionnaire completed by a third party of employees who meet the three conditions listed in Table 1. Section 2 shows previous research on assurance cases. Section 3 presents a procedure and two equations for quantitatively evaluating a sub-goal. Section 4 presents and discusses the results of a questionnaire survey on the two quantitative evaluation methods for assurance cases, the method using Eq. 1 and the method using Eq. 2. Section 5 concludes with future research subjects.

\section{Previous Research}

Safety case has been proposed as means for performing clarity, complete and reasonable discussion by Tim et al., in 1998. [5] It can be assured if the operation reaches an acceptable level in terms of safety between stakeholders by using the safety case. Assurance case [6] extends the discussion area to the whole quality of the discussedsystem including the "safety" proposed in safety case.

Assurance case is mainly an assurance method using six nodes, including Goal, Context, Strategy, Evidence, Monitoring and Undeveloped. [7][8] This study mainly uses Goal, Evidence and Monitoring.

In a previous study, Kelly et al. [9] proposed six attributes for assurance case review. It is, however, limited to the purpose of a review, and not aimed at quantitative evaluation.
Takai et al. [10] furthered the study, positioning the six attributes identified by Kelly as quality characteristics, namely "Coverage," "Dependency," "Definition," "Directness," "Relevance," and "Robustness," and proposed a method for identifying and measuring subattributes of the six main attributes.

This study, in contrast to the previous study, focused on six attributes of quality characteristics, proposing quantitative evaluation methods for Evidence and Monitoring from the perspective of each stakeholder.

The authors conducted literature review in the disciplinary of quality assurance with the themes of safety case, assurance case, and dependability case. After reviewing previous studies, the authors did not find any studies proposing quantitative evaluation methods for assurance cases.

The reason that no proposals on quantitative evaluation of Evidence and Monitoring were found can relate to the characteristics of assurance case:

The person who describes assurance case can assume that the described-system is assured with an assurance case assuring the system. When the stakeholders judge that the described-system is assured, they set Evidence and Monitoring. Evaluation of Evidence and Monitoring, namely review of assurance, is not required after certain period of time unless the described-system needs continuous improvement after it is previously assured. Conversely, work needs continuous improvement.

This study thus quantitatively evaluates the content that is described in regard to assurance cases, and thus is unique because it does not focus on quantitative evaluation of the structure of the assurance case.

\section{Quantitative Evaluation Methods}

The quantitative evaluation methods proposed in this paper consist of a procedure and two equations for quantitatively evaluating a sub-goal.

\subsection{Procedure of Quantitative Evaluation}

This study employs the following procedure, in which stakeholders evaluate Evidence and Monitoring for assurance cases. In this paper, "stakeholder" is defined as a person who is related to a sub-goal, or affected by other people in the process of achieving the sub-goal.

Step 1: A stakeholder explains to other stakeholders about an optional version of Evidence or Monitoring supporting a sub-goal, using assurance case.

Step 2: Each stakeholder evaluates the explained Evidence or Monitoring on a two-grade evaluation scale (Needs no improvement $=1$; Needs improvement $=0$ ), and writes the reason for "Needs improvement". 
Step 3: Stakeholders repeat Step 1 and Step 2 to evaluate each Evidence and Monitoring until they finish evaluating all.

All the Evidence, Monitoring and Undeveloped are thereby rated 0 or 1 respectively (Needs no improvement $=1$; Needs improvement $=0$; Undeveloped $=0$ ).

\subsection{Two Equations for Quantitative Evaluation}

This study proposes two equations for quantitatively evaluating a sub-goal.

One is the following equation to quantitatively evaluate an optional sub-goal (Ge1) by simply integrating the numbers of Evidence and Monitoring.

$$
G e 1=\frac{1}{\sum_{i=1}^{n}\left(K_{i}\right)} \sum_{i=1}^{n}\left(K_{i} S g_{i}\right)
$$

$K_{i}$ : Weighting value for respective Evidence, Monitoring and Undeveloped

$n$ : Total number derived for Evidence, Monitoring and Undeveloped assuring the goal to evaluate

$S g_{i}$ : Evaluation value respectively for Evidence, Monitoring and Undeveloped (Evidence $=1$; Monitoring $=$ $1 ;$ Undeveloped $=0$ )

Eq. 1 shows "the ratio of the internally-stipulated quality being assured." For example, if the ratio calculated using Eq. 1 is $100 \%$, we assume that all the relevant routines are documented in a manual with some supporting Evidence and Monitoring. A ratio less than $100 \%$, however, indicates that some of the routines are not documented.

The second equation Eq. 2 shown below takes into account stakeholders' opinion on Evidence and Monitoring to quantitatively evaluate an optional sub-goal (Ge2). Evidence and Monitoring are perceived favorably as good when all the stakeholders agree, and perceived unfavorably as bad if someone disagrees.

$$
G e 2=\frac{1}{\sum_{i=1}^{n}\left(K_{i}\right)} \sum_{i=1}^{n}\left(K_{i} S g B_{i}\right)
$$

$S g B_{i}$ : Evaluation value for Evidence or Monitoring (When the value is maximum $=1$; When the value is not maximum with one or more stakeholders perceiving the Evidence or Monitoring unfavorably $=0$; Undeveloped $=$ 0)

Eq. 2 indicates "the degree the improvement is considered unnecessary." For example, if all the stakeholders favorably perceive an optional type of Evidence supporting a sub-goal, the ratio calculated using Eq. 2 is $100 \%$, indicating that they agree that improvement is unnecessary. Conversely, if one or more stakeholders perceive the Evidence unfavorably, the ratio is $0 \%$, indicating that they agree that improvement is necessary.

Eq. 1 and Eq. 2 always have the relation of $G e 1 \geq G e 2$ since Eq. 2 takes account of stakeholders' opinion on Evidence and Monitoring in a deduction manner. $K_{i}$ is set at 1 for all of Evidence, Monitoring and Undeveloped. The calculation result as well as the percentage for one case is shown in Figure 1 and Figure 2 on assurance cases.

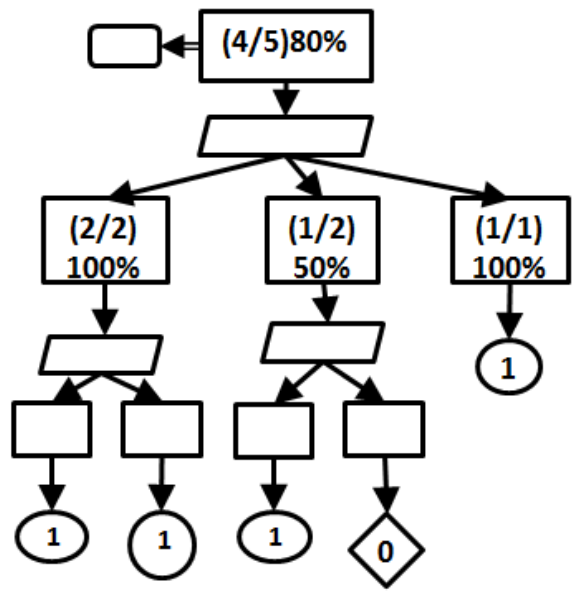

Figure 1: Calculation result Using Eq. 1

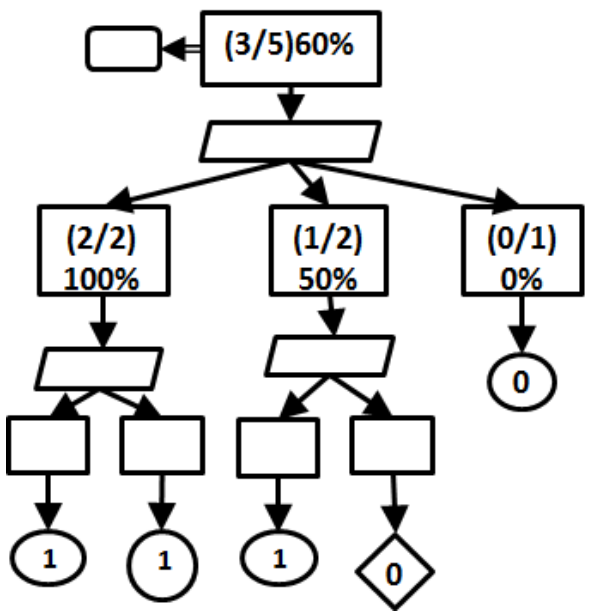

Figure 2: Calculation result Using Eq. 2

The rhombus shape represents Undeveloped. The Circle shape represents Evidence and Monitoring. The Square shape represents Goal. In the case of Figure 1, Evidence was valued 1 since the stakeholders set the Evidence and Monitoring. In the case of Figure 2, one or more stakeholders perceived the Evidence on the right side unfavorably. The Evidence was therefore valued 0 .

\section{Results And Evaluation}

This section describes the data collection method and data analysis method, followed by questionnaire results and discussions. 


\subsection{Data collection method}

This study employed a questionnaire completed by third party respondents for data collection. The respondents, selected to the meet three conditions listed in Table 1, were employees with routines who worked for Japanese manufacturing companies. The questionnaire included ten questions, to which the respondents answered regarding two quantitative evaluation methods for assurance cases, the method using Eq. 1 and the method using Eq. 2. Table 2 shows the questions assessing the "effectiveness" and "necessity" of the two methods. Responses were given on a seven-point ordinal scale, ranging from -3-"disagree," to +3-"agree," with 0 representing "neither agree nor disagree." Scores from +1 to +3 were assumed to be valid for business improvement.

Table 2: Correspondence of "Questionnaire question" and "Criteria of assessment".

\begin{tabular}{|c|l|}
\hline $\begin{array}{c}\text { Criteria of } \\
\text { assessment }\end{array}$ & \multicolumn{1}{|c|}{ Questionnaire statement } \\
\hline $\begin{array}{c}\text { Necessity of } \\
\text { Eq. 1 }\end{array}$ & $\begin{array}{c}\text { Quantitative visualization using Eq. 1 is } \\
\text { necessary for business improvement. }\end{array}$ \\
\hline $\begin{array}{c}\text { Effectiveness } \\
\text { of Eq. 1 }\end{array}$ & $\begin{array}{l}\text { Quantitative visualization using Eq. 1 is } \\
\text { effective for business improvement. }\end{array}$ \\
\hline $\begin{array}{c}\text { Necessity of } \\
\text { Eq. 2 }\end{array}$ & $\begin{array}{l}\text { Quantitative visualization using Eq. 2 is } \\
\text { necessary for business improvement. }\end{array}$ \\
\hline $\begin{array}{c}\text { Effectiveness } \\
\text { of Eq. 2 }\end{array}$ & $\begin{array}{l}\text { Quantitative visualization using Eq. 2 is } \\
\text { effective for business improvement. }\end{array}$ \\
\hline
\end{tabular}

The questionnaire also included free descriptive space so that respondents could indicate situations when the two quantitative evaluation methods for assurance cases, the method using Eq. 1 and the method using Eq. 2, are likely to be useful.

\subsection{Data analysis method}

Based on the questionnaire responses, this study assesses the "difference of effectiveness" in employing two quantitative evaluation methods for assurance cases, the method using Eq. 1 and the method using Eq. 2. Free descriptive answers are used for analysis.

For analyzing the data collected, free descriptive answers are used as the data and analyzed by the following procedure, using qualitative coding methods for qualitative data analysis. [11] The reason being that, for example, if there is any difference in the purpose of employing the two evaluation methods proposed, we assume that the difference would come out accordingly in the free descriptive answers. However, if there is no difference in the purpose of employing the two evaluation methods proposed, no difference would come out in the free descriptive answers.
Step 1: View the free answers for the method using Eq. 1, set the viewpoint for Affinity Diagram grouping (Step 2). It was set in this study as "purpose of evaluation using the proposed equation," in order to show for what purpose the proposed method is useful.

Step 2: Look for, from the aforementioned viewpoint, the descriptions for the method using Eq. 1 that seem to be related, and sort them into groups.

Step 3: Write titles for each group that summarizes the essence of the group, at a slightly higher level of abstraction (called "Open coding results of the method using Eq. 1" in this study).

Step 4: Compare with "Open coding results of the method using Eq. 1" the free answers for the method using Eq. 2.

Step 5: For the method using Eq. 2, look for, from the aforementioned viewpoint, the descriptions that seem to be related, and sort them into groups under the same title as the method using Eq. 1, or new groups for different descriptions (called "Open coding results of the method using Eq. 2" in this study).

Step 6: Write titles for the groups newly made for the method using Eq. 2.

Step 7: Make a table of "Open coding results of the method using Eq. 1" and "Open coding results of the method using Eq. 2" to highlight the differences.

This study ensured the validity of the analysis by having one researcher specializing in qualitative research methods and another specializing in assurance cases review the analysis results. [12]

\subsection{Questionnaire result}

The questionnaire survey was conducted between June 18, 2014, and August 18, 2014. Of the 75 people contacted, there were 3 people who did not respond, and 72 valid respondents.

\subsubsection{Profile of survey participants}

Profiles of the survey respondents are shown in Table 3 and Table 4.

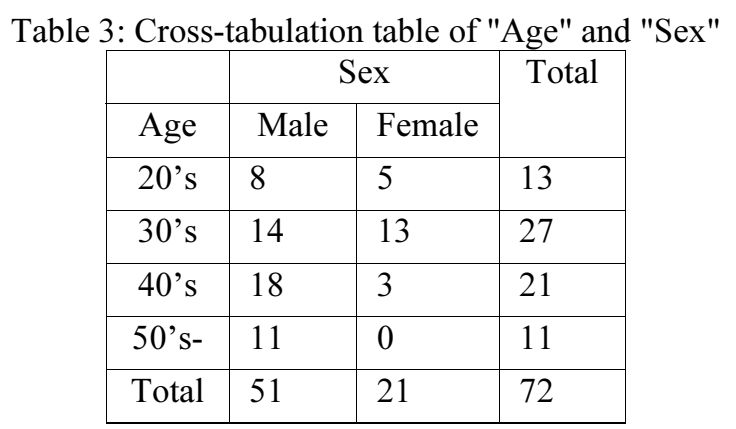


Table 4: Cross-tabulation table of "Sex" and "whether or not the respondent has a subordinate"

\begin{tabular}{|c|l|l|l|}
\hline Sex & \multicolumn{2}{|c|}{ Subordinates } & Total \\
& $\begin{array}{c}\text { Have one or } \\
\text { more } \\
\text { subordinates }\end{array}$ & $\begin{array}{c}\text { Have no } \\
\text { subordinate }\end{array}$ & \\
\hline Male & 15 & 36 & 51 \\
\hline Female & 15 & 6 & 21 \\
\hline Total & 51 & 21 & 72 \\
\hline
\end{tabular}

Table 5: Results of paired t-test.

\begin{tabular}{|l|c|c|c|}
\hline & $\mathrm{T}$ & $\mathrm{df}$ & $\begin{array}{c}\mathrm{p} \text { value } \\
\text { (two-tailed } \\
\text { test) }\end{array}$ \\
\hline Necessity & 1.650 & 71 & 0.103 \\
\hline Effectiveness & 2.882 & 71 & 0.005 \\
\hline
\end{tabular}

Table 6: Results of Necessity and Effectiveness.

\begin{tabular}{|l|l|l|l|}
\hline & Ave. & $\begin{array}{l}\text { Standard } \\
\text { deviation }\end{array}$ & $\begin{array}{c}\text { Standard } \\
\text { deviation } \\
\text { of Ave. }\end{array}$ \\
\hline $\begin{array}{l}\text { Necessity of } \\
\text { Eq. 1 }\end{array}$ & 5.54 & 1.331 & 0.157 \\
\hline $\begin{array}{l}\text { Necessity of } \\
\text { Eq. 2 }\end{array}$ & 5.24 & 1.515 & 0.179 \\
\hline $\begin{array}{l}\text { Effectiveness } \\
\text { of Eq. 1 }\end{array}$ & 5.69 & 1.109 & 0.131 \\
\hline $\begin{array}{l}\text { Effectiveness } \\
\text { of Eq. 2 }\end{array}$ & 5.11 & 1.683 & 0.198 \\
\hline
\end{tabular}

Table 7: Open coding results of Eq. 1 and Eq. 2.

\begin{tabular}{|c|c|c|}
\hline Open coding results & Eq. 1 & Eq. 2 \\
\hline $\begin{array}{l}\text { Grasping necessity of work } \\
\text { improvement }\end{array}$ & 0 & 35 \\
\hline Setting a goal in figures & 34 & 14 \\
\hline Clarifying priorities & 9 & 24 \\
\hline $\begin{array}{l}\text { Judging necessity of creating a } \\
\text { manual }\end{array}$ & 18 & 0 \\
\hline Having a common view & 16 & 11 \\
\hline Taking over one's work & 6 & 0 \\
\hline Sharing one's work & 5 & 0 \\
\hline $\begin{array}{llll}\begin{array}{l}\text { Grasping employees' view } \\
\text { chronological order }\end{array} & & \text { in } \\
\end{array}$ & 0 & 4 \\
\hline Grasping established level of work & 3 & 0 \\
\hline Risk avoidance & 2 & 1 \\
\hline Cost reduction & 0 & 1 \\
\hline Grasping human resources & 0 & 1 \\
\hline
\end{tabular}

\subsubsection{Questionnaire results on a seven-point ordinal scale}

The results of the paired t-test for "necessity" and "effectiveness" the two equations proposed are shown in Tables 5 and 6 .

\subsubsection{Qualitative coding result of free descriptive space}

Table 7 shows the results gained through the steps of Section 4.2.

\subsection{Discussion}

Firstly, we discuss the results presented in Section 4.3.2.

As shown in Table 5, this study failed to collect a statistically significant number of questionnaires, and thus makes the assessment based on descriptive study. [13]

For "necessity," the trend was confirmed to be statistically significant as to the average value, with Table 5 showing $p=0.103$. For "effectiveness," the difference was confirmed to be statistically significant as to the average value, with Table 5 showing $p=0.005$. Overall the evaluation of Eq. 1 is thus better than Eq. 2 based on the descriptive study. We found through the descriptive study that Eq.1 suggested more efficacy than Eq.2 for work improvement.

Secondly, we discuss the evaluation of Eq. 1 shown in Table 7.

"Setting a goal in figures" means that recognizing the presence of a manual makes it easier to set for each type of work a target value for improvement, as one can aim at creating manuals to stipulate all work.

"Clarifying priorities" refers to the fact that one can set priorities to create manuals based on one's understanding on which manual is currently unprepared, referring to the ratio of manual availability shown quantitatively.

"Judging necessity of creating a manual" refers to the fact that one can judge the necessity of creating a manual depending on whether there is a manual or not.

"Having a common view" refers to the fact that knowing if there is a manual makes it possible to inform employees of whether they are equipped with manuals; they would not have a chance to know the availability of manuals without the method using Eq. 1. For example, one could recognize the possibility that one is internally forced to make an improvement due to the discrepancy of manual availability rates between one's team and other teams.

"Taking over one's work" means that knowledge of the presence of a manual could be used as an indicator to judge whether taking over one's work is difficult or not.

"Sharing one's work" means that one can see if it is easy to change the current work sharing, based on whether or not there is a manual. 
"Grasping established level of work" refers to the fact that recognition of whether or not there is a manual could be used as an indicator to show if the contents of the work are fixed.

"Risk avoidance" refers to the fact that recognition of whether or not there is a manual makes it possible to figure out whether such work that is important yet not stipulated in a manual can be stably continued. With the method using Eq. 1, one is likely to avoid risks by taking necessary measures.

This method using Eq. 1 can therefore contribute to the benefit of stakeholders in terms of having a common view of the work, considering measures for work improvement and risk avoidance, and setting a goal.

Analyzing the effectiveness of the proposed methods for work improvement based on the results of quantitative evaluation of assurance cases, we found that that the method using Eq. 1 is more effective than that using Eq. 2 in that:

-Judging necessity of creating a manual

-Taking over one's work

-Sharing one's work

-Grasping established level of work

Thirdly, we discuss the evaluation of Eq. 2 shown in Table 7.

"Grasping necessity of work improvement" refers to the fact that one can recognize in figures whether considering work improvement is necessary.

"Setting a goal in figures" refers to the fact that recognition to what extent work improvement is necessary makes it possible to pursue improvement with an aim of lowering the evaluation value.

"Clarifying priorities" refers to the fact that recognition of the extent of necessary work improvement makes it possible to implement improvement activities with a focus on the work with lower evaluation values.

"Having a common view" refers to the fact that recognition of the extent of necessary work improvement makes it possible to inform employees of the range of work improvement required, when they would not have a chance to know the necessity of work improvement in figures without the method using Eq. 2.

"Grasping employees' view in chronological order" refers to the fact that recognition of the extent of necessary work improvement makes it possible, through constant use of the method using Eq. 2, to grasp over time the change of employees' awareness on the necessity of work improvement. For example, one can see, in figures, the change of employees' views, comparing this year and next year.

"Risk avoidance" refers to the fact that recognition of the extent of necessary work improvement makes it possible to identify the degree to which work improvement is required, and thereby find the fatal risks.

"Cost reduction" refers to the fact that recognition of the extent of necessary work improvement makes it possible for a company to centrally manage the identification of the range work improvement required. With the method using Eq. 2, the cost of identifying the range of required work improvement can thereby be reduced in terms of the current cases of individual organizations involved in identifying activities.

"Grasping human resources" refers to the fact that recognition of the extent of necessary work improvement makes it possible to grasp the range of required work improvement, and thereby maximize the volume of human resources necessary for work improvement.

This method using Eq. 2 can therefore contribute to the benefit of stakeholders in terms of having a common view on work improvement, considering measures for work improvement, grasping the employees' view, and achieving cost reduction.

Analyzing the effectiveness of the proposed methods for work improvement, we found based on the results of quantitative evaluation of Assurance case that the method using Eq. 2 is more effective than that using Eq. 1 in that:

-Grasping necessity of work improvement

-Grasping employees' view in chronological order

-Cost reduction

-Grasping human resources

\section{Conclusions}

The purpose of this study was to confirm that assurance cases are useful for work improvement. We used the results from the quantitative evaluation of assurance cases. As a result, the study proposed two methods of quantitatively evaluating work quality with the use of assurance cases, and thereby assessed effectiveness and necessity of the two methods through a questionnaire survey completed by a third party of employees. As a result, the results were statistically significant for both "effectiveness" and "necessity." In addition, it was confirmed that Eq. 1 suggested more efficacy than Eq. 2.

The method using Eq. 1 is more effective than that using Eq. 2 in that:

-Judging necessity of creating a manual

-Taking over one's work

-Sharing one's work

-Grasping established level of work

The method using Eq. 2 is more effective than that using Eq. 1 in that:

-Grasping necessity of work improvement

-Grasping employees' view in chronological order

-Cost reduction

-Grasping human resources

Creating the criteria for evaluating the calculation results obtained from two formulas is a future research subject. 


\section{Acknowledgments}

N.Kobayashi was supported this paper by Doctoral Student Aid Program from Keio University.

\section{References}

[1]ISO26262-10-2012(E)-Road vehicles-Functional safety-Part 10: Guideline on ISO26262

[2]ISO15026-2-2011.Systems and Software engineering Part2: Assurance case

[3]N.Kobayashi, M.Kawase, S.Shirasaka: A Proposal for an Assurance Case Description Method -Aiming to Tackle Challenges in Work-Related Communication-, Journal of Japan Associations for Management Systems, Vol.33,No.2, (2016).

[4]Y. Masuzawa: On Structured Manuals Analysis and Design for Japanese Enterprises, Americas Conference on Information Systems 2000 Proceedings, (2000), 14211427.

[5]Tim Kelly.: Arguing Safety - A Systematic Approach to Managing Safety Case, Ph.D. Thesis, University of York., (1998).

[6]Catherine Menon, Richard Hawkins, John McDermid.: Defence Standard 00-56 Issue 4: Towards EvidenceBased Safety Standards, Proceedings of the Seventeenth Safety-Critical Systems Symposium, (2009), 223-243

[7]GSN Community.: GSN COMMUNITY STANDARD VERSION 1, Origin Consulting (York), (2011)

[8]Yutaka Matsuno, Hiroki Takamura, Yutaka Ishikawa: A Dependability Case Editor with Pattern Library, IEEE 12th International Symposium on High Assurance Systems Engineering, (2010), 170-171

[9]T. Kelly: Reviewing Assurance Arguments - A StepBy-Step Approach, Dependable Systems and Networks (DSN), (2007).

[10]T. Takai, Y. Matsuno: ASHUARANSUKESUKYOIKUNOTAMENOKIJYUTUENSHUUTOSONOHYOUKAH OU (Writing exercises and evaluation method for the Assurance Case education), 10th Dependable System Workshop, Japan Society for Software Science and Technology, (2012).

[11]A. Strauss and J. Corbin: Basics of Qualitative Research: Techniques and Procedures for Developing Grounded Theory, third edition, London, Sage Publications, (2008).

[12]N. Golafshani: Understanding Reliability and Validity in Qualitative Research, The Qualitative Report Volume 8 Number 4 December 2003, (2003), 597-607.

[13]D. F. Polit, B. P. Hungler: Nursing Research: Principles and Methods (6th Ed.), (Philadelphia, Lippincott, 1999). 
